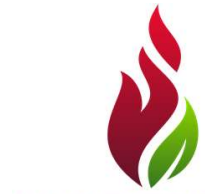

SUSTENERE

Publishing Corporation

\section{BALANÇO ENERGÉTICO DO CAPIM ELEFANTE VS EUCALIPTO}

\section{RESUMO}

O presente trabalho apresenta um estudo comparativo entre duas biomassas, o eucalipto e o capim elefante (também conhecido como Miscanthus), avaliando o balanço energético de cada biomassa para atender a demanda energética de uma indústria cerâmica padrão. Além disso, foram analisadas duas formas de compactação para o capim elefante, o enfardamento e a briquetagem, e a briquetagem do eucalipto derivado de duas condições de plantio, o espaçamento e o adensado. Também foram comparadas duas formas de secagem, a solar e a induzida. Os dados empregados para o eucalipto na análise foram extraídos das bibliografias pertinentes e, para o capim elefante, de um plantio piloto em Panorama - SP, com análises em laboratórios do IPT - SP. Os resultados mostram a viabilidade, do ponto de vista energético, do capim elefante, com uma razão máxima de balanço de até 20,65 . Já o eucalipto, fonte energética já consolidada no mercado, aparece com uma razão máxima de 11,35. Conclui-se que o capim elefante possui uma perspectiva otimista como fonte energética, se sobressaindo ao eucalipto.

PALAVRAS-CHAVE: Biomassa; Bioenergia; Briquetagem; Enfardamento; Cerâmica Vermelha.

\section{ENERGY BALANCE OF ELEPHANT GRASS VS EUCALYPTUS}

\section{ABSTRACT}

This work presents a comparative study between two biomasses, eucalyptus and elephant grass (known also as Miscanthus), evaluating the energy balance of each biomass to meet the energy demand of a standard ceramic industry. In addition, it was analyzed two forms of compaction for elephant grass, baling and briquetting, and briquetting of eucalyptus derived from two conditions of planting, conventional and dense. Also, the study compared two ways of drying, solar and induced. The data used for eucalyptus in the analysis were drawn from the relevant bibliographies and, for elephant grass, from a pilot planting in Panorama - SP, with analyses in laboratories at IPT - SP. The results show the feasibility, from an energetic point of view, to elephant grass, with a maximum balance ratio of 20.65 . While eucalyptus, energy source already consolidated in the market, appears with a maximum ratio of 11.35. It was concluded that elephant grass has an optimistic outlook as an energy source, excelling above eucalyptus.

KEYWORDS: Biomass; Bioenergy; Briquetting; Baling; Red Ceramic.
Engineering Sciences, Aquidabã, v.3, n.1, Dez 2014, Jan, Fev, Mar, Abr, Mai, Jun, Jul, Ago, Set, Out, Nov 2015.

\section{ISSN 2318-3055}

\section{SECTION: Articles}

TOPIC: Engenharia Agronômica e Agrícola

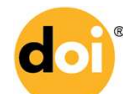

DOI: 10.6008/SPC2318-3055.2015.001.0002

Vicente Nelson Giovanni Mazzarella Instituto de Pesquisas Tecnológicas do Estado de São Paulo, Brasil

http://lattes.cnpq.br/7613079392736269 mazza@ipt.br

\section{Henrique Jun Muramatsu Seguchi}

Instituto de Pesquisas Tecnológicas do Estado de São Paulo, Brasil

http://lattes.cnpq.br/8409964137864450

hseguchi@ipt.br

\section{Paulo Henrique Ferreira}

Instituto de Pesquisas Tecnológicas do Estado de São Paulo, Brasil

http://lattes.cnpq.br/9243273577152243 paulohf@ipt.br

Received: $10 / 08 / 2015$

Approved: 26/10/2015

Reviewed anonymously in the process of blind peer.

\section{Referencing this:}

MAZZARELLA, V. N. G.; SEGUCHI, H. J. M.; FERREIRA, P. H. Balanço energético do capim elefante vs eucalipto. Engineering Sciences, Aquidabã, v.3, n.1, p.19-36, 2015 DOI: http://doi.org/10.6008/2318-3055.2015.001.0002 


\section{INTRODUÇÃO}

O uso atual de combustíveis fósseis, que geram diversos tipos de gases, é o principal responsável pela emissão de gases do efeito estufa (Quadro 1), contribuindo com a aceleração do aquecimento global, questão que está sendo discutida por autoridades, cientistas e políticos do mundo inteiro.

Quadro 1: Equivalência de geradores de GEE em termos de CO2 (IPCC, 2007 - Adaptado)

\begin{tabular}{|c|c|}
\hline GEE & Potencial de aquecimento global $\mathrm{CO}_{2}$ equivalente \\
\hline $\mathrm{CO}_{2}-\mathrm{Dióxido} \mathrm{de} \mathrm{carbono}_{\mathrm{CH}_{4}-\text { Metano }}$ & $\mathbf{2 1}$ \\
\hline $\mathrm{N}_{2} \mathrm{O}-$ Óxido Nitroso & 310 \\
\hline $\mathrm{HFCs}-$ Hidrofluorcarbonetos & $140-11700$ \\
\hline $\mathrm{PFCs}-$ Perfluorcarbonetos & $\mathbf{6 5 0 0 - 9 2 0 0}$ \\
\hline $\mathrm{SF}_{6}-$ Hexafluoreto de enxofre & 23900 \\
\hline
\end{tabular}

No sentido de reverter essa situação, o protocolo de Kyoto, tratado internacional que entrou em vigor em 2005, ratificado por 55 países, visa à redução da emissão dos gases de efeito estufa na atmosfera. Ele estabelece metas para os principais países emissores, discutidas em eventos sucessivos como em Cancun - México (2010), Durban - África do Sul (2011), Rio de Janeiro - Brasil (“Rio+20”, 2012), Varsóvia - Polônia (2013), tendo criado, como forma de incentivo, os créditos de carbono.

A Conferência das Partes da Convenção das Nações Unidas sobre Mudança do Clima (COP21), em Paris (França), deverá assinar o maior acordo climático do mundo, substituindo o Protocolo de Kyoto pelo Protocolo de Paris.

No cenário energético mundial, a tendência de substituir gradativamente energias fósseis por renováveis coloca a biomassa em um lugar de destaque nos próximos anos (Figura 1). Isto é importante particularmente para o Brasil, pelo conjunto de condições favoráveis que o país apresenta para o crescimento de certas biomassas como combustível.

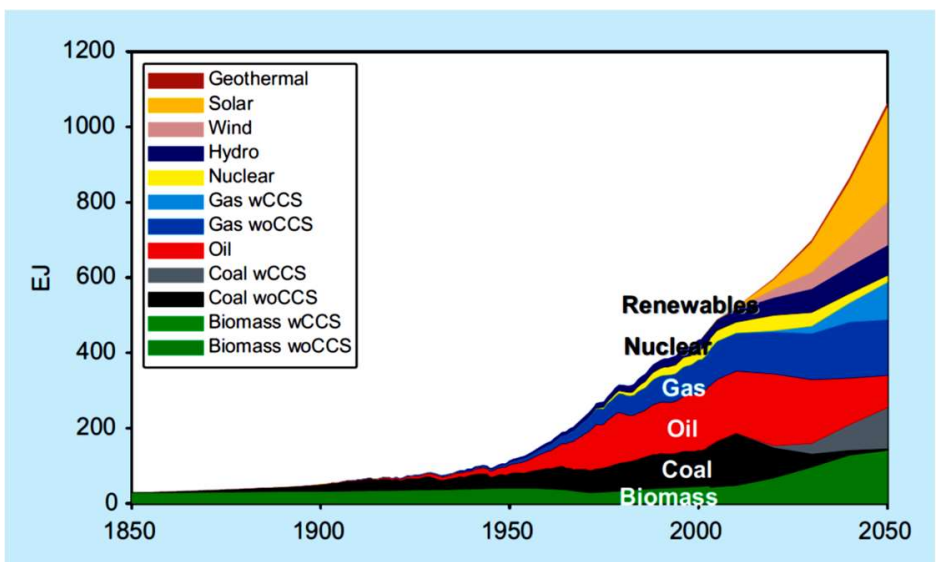

Figura 1: Evolução do Uso de Energia Primária até 2050 (GEA, 2012) wCCS: With Carbon Capture and Storage - Com Captura e Armazenamento de Carbono woCCS: Without Carbon Capture and Storage - Sem Captura e Armazenamento de Carbono 
O Quadro 2 aponta a contribuição de energias renováveis no Brasil e, em particular, da biomassa, cuja previsão de crescimento, no período 2015 - 2050, é de 47,5\%, maior do que o aumento do consumo total, de $31,1 \%$. Vê-se, também, que a biomassa contribui, ao final do período, com $35 \%$, em torno de $52 \%$ dos $67,2 \%$ de todas as fontes renováveis.

Quadro 2: Demanda de Energia Primária, Cenário Revolução Energética (PJ/ano) (Greenpeace, 2013 -

\begin{tabular}{|c|c|c|c|c|c|c|c|}
\hline & \multicolumn{7}{|c|}{ Adaptado) } \\
\hline & 2010 & $\begin{array}{c}2015 \text { (Média } \\
\text { Calculada) }\end{array}$ & 2020 & 2030 & 2040 & 2050 & $\begin{array}{c}\text { Variação } \\
2015 \text { - 2050 }\end{array}$ \\
\hline Total & 11347 & 12916 & 14485 & 16212 & 16709 & 16929 & $+31,1 \%$ \\
\hline Fósseis & 6003 & 7052 & 8101 & 8009 & 6844 & 5552 & \\
\hline Carvão & 638 & 655 & 672 & 463 & 231 & 177 & \\
\hline Gás Natural & 973 & 1417 & 1860 & 2171 & 1849 & 1483 & \\
\hline Petróleo & 4392 & 4981 & 5570 & 5375 & 4764 & 3892 & \\
\hline Nuclear & 158 & 166 & 174 & 121 & 0 & 0 & \\
\hline Hidrelétricas & 1452 & 1557 & 1661 & 1779 & 1885 & 1892 & \\
\hline Eólica & 8 & 62 & 115 & 370 & 661 & 1004 & \\
\hline Solar & 15 & 55 & 95 & 461 & 1390 & 2308 & \\
\hline Biomassa & 3711 & 4020 & 4328 & 5419 & 5791 & 5930 & $+47,5 \%$ \\
\hline Geotérmica & 0 & 6 & 11 & 50 & 120 & 203 & \\
\hline Energia Oceânica & 0 & 0 & 0 & 4 & 18 & 40 & \\
\hline Contribuição das Renováveis & 5186 & 5698 & 6210 & 8083 & 9865 & 11377 & $+99,7 \%$ \\
\hline Contribuição das Renováveis (\%) & $45,7 \%$ & $44,1 \%$ & $42,9 \%$ & $49,9 \%$ & $59,0 \%$ & $67,2 \%$ & \\
\hline Contribuição da Biomassa (\%) & $32,7 \%$ & $31,1 \%$ & $29,9 \%$ & $33,4 \%$ & $34,7 \%$ & $35,0 \%$ & \\
\hline
\end{tabular}

Assim, a biomassa aparece como uma opção extremamente promissora dentre as fontes energéticas renováveis na atualidade, sendo a única que interage com o carbono atmosférico. Por sua própria natureza, através da fotossíntese, ela captura o dióxido de carbono, dissocia-o, liberando o oxigênio e integrando carbono em sua composição celulósica, reduzindo a quantidade presente na atmosfera. Apesar de o gás carbônico ser liberado na queima da biomassa, parte do carbono da biomassa ainda permanece no solo como matéria orgânica residual da colheita e, principalmente, no extenso sistema radicular das plantas.

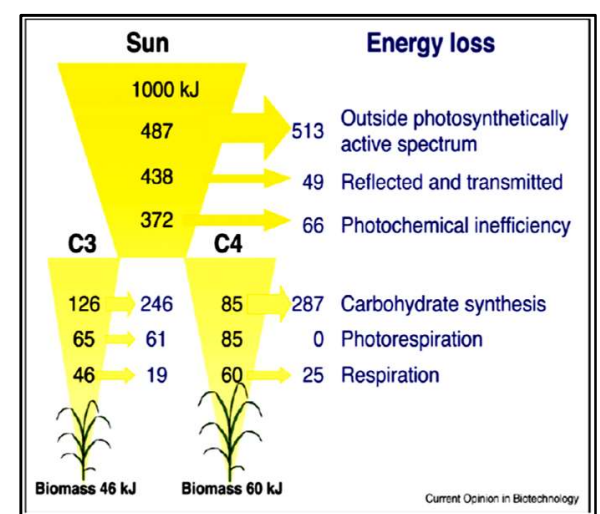

Figura 2: Eficiência na Conversão de Energia Solar: C3 x C4 (Zhu et al., 2008)

Visto isso, o capim elefante, gramínea originária da África, ou da Ásia (segundo os ingleses), conhecida por sua resistência a estiagens e a infestações de pragas e facilmente adaptável a diferentes condições edafoclimáticas, mostra-se como uma fonte alternativa de energia em destaque, devido à sua alta produtividade e ciclo curto (depois de 6 meses já é possível realizar uma colheita). Por ser uma gramínea do tipo C-4, classificação que mede a atividade fotossintética, ela se apresenta mais vantajosa que o eucalipto, do tipo C-3, sendo mais 
econômica quanto à absorção de água e com uma alta eficiência na conversão de energia solar em energia química, armazenada na planta, obtendo-se maior produtividade por área e por ano (Figura 2) (SILVA, 2010).

O eucalipto é uma das principais espécies conhecidas para geração de energia renovável. Porém, comparado ao capim elefante, o eucalipto mostra-se relativamente inferior quanto à produtividade, ciclo e custo. Uma variável a ser considerada nessas biomassas é o custo de transporte, pois possuem uma densidade aparente muito baixa, resultando na necessidade de compactá-las, o que facilitaria também o manuseio e o processamento para queima em fornalhas.

A compactação, por sua vez, possui a capacidade de transformar as fibras individuais em massa densa, não se utilizando de nenhum processo químico ou aglutinante. Assim, tem-se uma simplificação da logística e do manuseio da biomassa, reduzindo custos de transportes e os riscos contra princípio de incêndio, melhorando a homogeneização e possibilitando sua adaptação fácil e barata em caldeiras existentes de combustíveis fósseis para pellets ou briquetes. Outra forma de compactação é a bripellagem, ou obtenção de mini-briquetes chamados bripells, com ø (diâmetro) de $40 \mathrm{~mm}$, que tende a ser uma aproximação entre o baixo custo do briquete e a comodidade permitida quando se requer um determinado nível de automação.

Sabe-se que a pelletização é uma das formas de compactar os resíduos florestais amplamente disseminada na Europa, sendo os pellets muito utilizados em residências, hospitais, escolas e indústrias. Ainda assim, a briquetagem, com seu processo de extrusão ou prensagem, é menos exigente em energia do que a pelletização, além do custo ser relativamente inferior.

No Brasil, o processo de compactação por briquetagem foi mais aceito, pois possui algumas vantagens determinantes, já citadas anteriormente, e, como denotou Bhattacharya (2002 citado por DIAS, 2012), "o emprego de briquetes está difundido em países em desenvolvimento e o de pellets em países mais desenvolvidos, pois requer maior nível de automação e controle do processo".

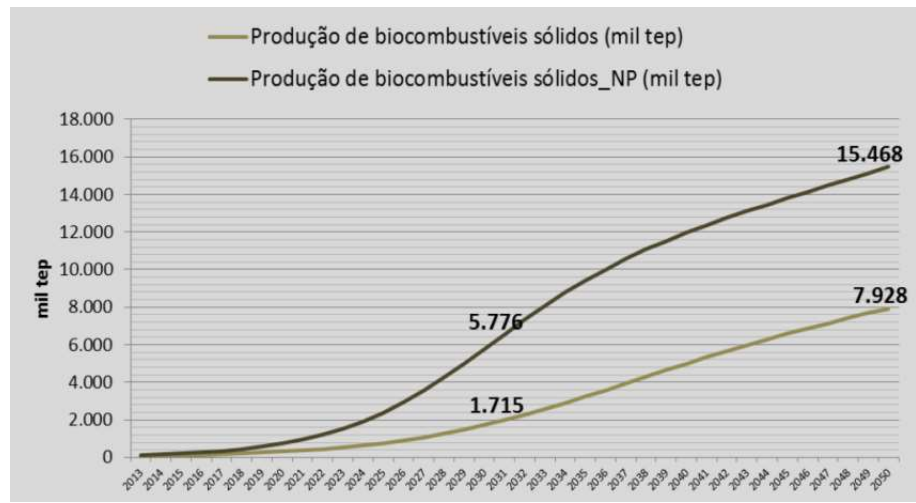

Figura 3: Projeção da penetração dos biocombustíveis sólidos versus potencial de biomassa sólida disponível na trajetória de sensibilidade de Novas Políticas

tep: toneladas equivalentes de petróleo equivale a $41,868 \mathrm{GJ}$

Além disso, segundo os Estudos da Demanda de Energia para 2050 (EPE, 2014):

A competitividade dos biocombustíveis sólidos atualmente ainda é restrita, principalmente por conta dos custos de biomassa e custos logísticos, o que faz 
esses combustíveis apresentar custos da ordem de $\mathrm{R} \$ 200 / \mathrm{t}$ ou $\mathrm{R} \$ 13 / \mathrm{GJ}$ (BRIPELL, 2010 e EPE, 2014, no prelo). O estabelecimento das condições expostas do cenário de longo prazo da biomassa serão fatores de redução de custos tanto das biomassas como dos custos logístico, fazendo com que esses custos caiam pela metade no final do período.

Ainda segundo a EPE - Empresa de Pesquisa Energética (2014), A projeção do uso de biocombustíveis sólidos (2013-2050), comparando o cenário atual com o de Novas Políticas, visando seu incentivo, prevê um crescimento constante, como mostrado na Figura 3.

\section{METODOLOGIA}

A metodologia para análise e comparação entre as diferentes alternativas de compactação do capim elefante, briquetagem e enfardamento, e de sua comparação com a briquetagem do eucalipto, para duas formas plantio: convencional e adensado, tanto para a secagem solar quanto para a induzida, inclui algumas hipóteses e premissas adotadas, apresentadas e explicadas a seguir.

Parte dos dados de entrada do capim elefante, do plantio até a secagem, foi coletada de um plantio piloto (Figuras 4 e 5 do plantio e colheita, respectivamente) de projeto entre o IPT Instituto de Pesquisas Tecnológicas e a Prefeitura Municipal de Panorama, figurando como parte interessada a INCOESP - Cooperativa das Indústrias Cerâmicas Vermelhas do Oeste Paulista, realizado em Panorama-SP.

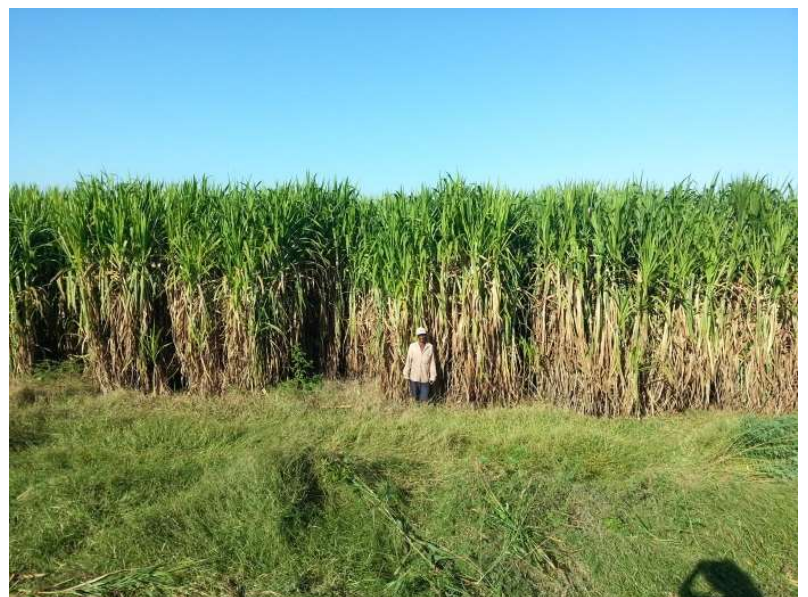

Figura 4: Plantio em Panorama-SP (Mai/15)

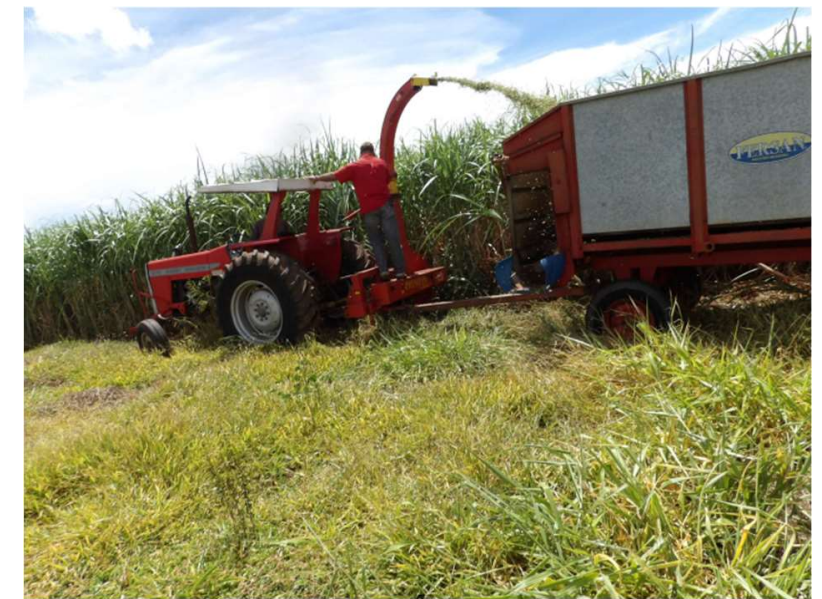

Figura 5: Colheita do Plantio (Jul/15)

Foram considerados apenas os dados da variedade Cameroon para este estudo, pois foi a que apresentou o melhor resultado de produtividade, ou seja, um reflexo de que possui a melhor compatibilidade com o clima e o solo da região. Até o momento, foi realizada apenas a primeira colheita semestral.

Para este estudo, foram considerados 2 alternativas teóricas de secagem, a secagem "solar", com uso de um revolvedor tipo ancinho (enleirador e espalhador) tracionado por um trator, e a secagem "induzida", com uso de um gerador de ar quente e um tambor rotativo, onde o calor provêm da queima de uma parcela do capim colhido. 
O balanço energético teve por objetivo teórico atender uma indústria cerâmica de pequeno porte, tomada como padrão, com capacidade de produção de 500 mil blocos por mês, sendo cada bloco de, aproximadamente, $2 \mathrm{~kg}$ e totalizando uma necessidade energética por volta de 3,894 MJ/peça, o equivalente a 1947 GJ/mês de energia para secagem dos blocos, dados da Secretaria de Geologia, Mineração e Transformação Mineral (2007), que será proveniente da biomassa a ser queimada.

A produtividade ${ }^{1}$ média do capim elefante no projeto de Panorama, de, aproximadamente, $87,9 \mathrm{tm} . \mathrm{v} . / \mathrm{ha}$, com $61,21 \%$ de umidade, foi estimada como a média extraída da produção da primeira colheita semestral, proveniente do plantio dos 15.642 toletes/ha, e interpolada como sendo $60 \%$ da produtividade anual, resultando numa estimativa média da segunda colheita de $58,6 \mathrm{tm} . \mathrm{v} . / \mathrm{ha}$, totalizando $146,5 \mathrm{tm} . \mathrm{v} . /$ ha.a, com teor de umidade médio de $61,21 \%$, ou 56,8 tm.s./ha.a.

Os dados das operações de plantio e colheita do eucalipto foram avaliados para duas situações de plantio, que produzem resultados bem diferenciados, o convencional (plantio tradicional no Brasil) e o adensado (plantio energético pouco usual e ainda em estudo). Para o plantio convencional, teve-se como fonte Rodigheri et al. (2001, adaptado), com uma produtividade de, aproximadamente, 19,5 tm.s./ha.a, estimada como o valor médio anual de 3 colheitas, a cada 7 anos, durante um período de 21 anos, de um plantio de 1.666 mudas/ha e espaçamento de $3 \times 2 \mathrm{~m}$. Para o plantio adensando, teve-se como fonte Dinardi (2014), com eucalyptus spp. com uma produtividade de, aproximadamente, $34,9 \mathrm{tm} . \mathrm{s}$./ha.a, estimada como o valor anualizado de 1 colheita, após 36 meses, de um plantio de 7.334 mudas/ha e espaçamento de $3 \times 0,5 \mathrm{~m}$. Outro texto de apoio utilizado na verificação dos condições e parâmetros de plantio do eucalipto foi Wilcken et al. (2008).

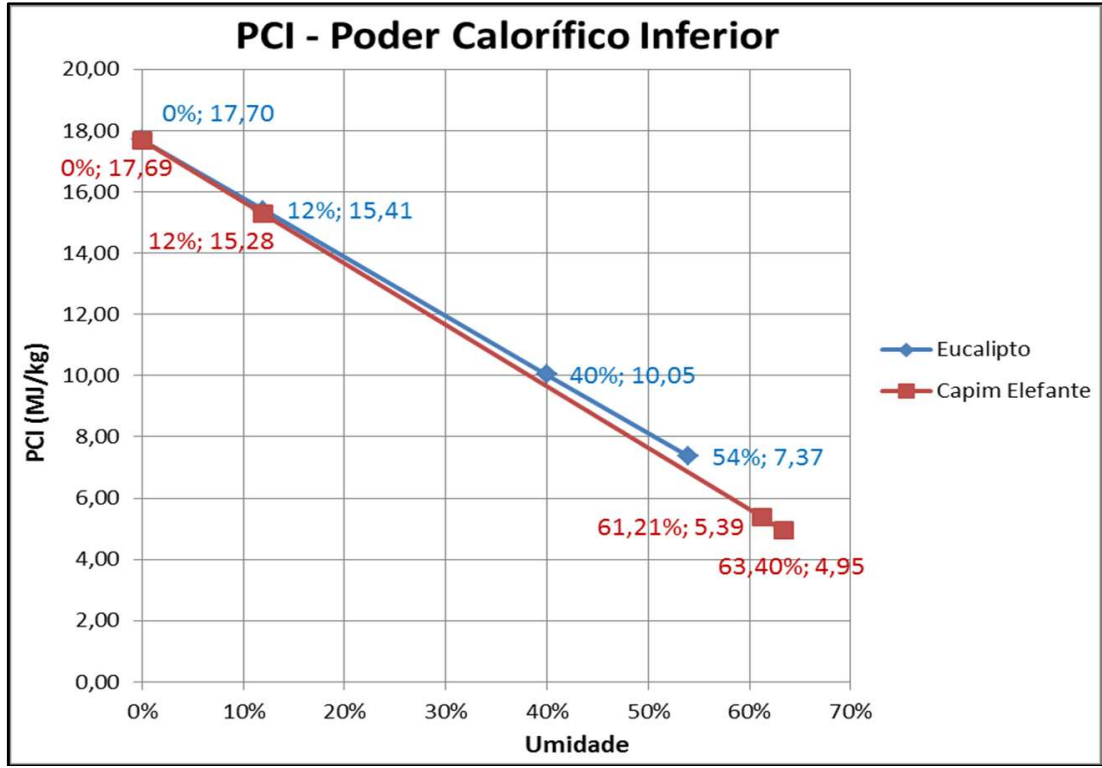

Figura 6: Variação do PCl com a Umidade.

\footnotetext{
${ }^{1}$ As unidades de medida de produtividade comuns adotadas para este estudo são: tonelada de massa verde / hectare $\mathrm{x}$ ano (tm.v./ha.a) e tonelada de massa seca / hectare $x$ ano (tm.s./ha.a).
} 
Para efeitos de compactação, considerou-se o estado final, tanto do capim elefante quanto do eucalipto, como sendo com um teor de umidade de 12\% (QUIRINO, 2002). Já o estado inicial, referente à massa verde colhida, no caso do capim elefante, foi considerado o valor médio medido no plantio piloto, enquanto para o eucalipto, foi considerado o valor encontrado na literatura, de aproximadamente 54\% (LANA, 2012).

$\mathrm{O} \mathrm{PCl}$ - poder calorífico inferior, usado na estimativa da energia disponível na queima da biomassa, tanto do capim elefante quanto do eucalipto, com $12 \%$ de umidade, foi estimado com base na curva característica linear de variação da capacidade calorífica em função da umidade, construída no Excel, a partir dos pontos pertinentes, e apresentada na Figura 6 a seguir:

Para o capim elefante, os 2 pontos mínimos para gerar a curva do poder calorífico foram obtidos com medidas feitas em laboratório, obtendo-se os valores de $17,69 \mathrm{MJ} / \mathrm{kg}$, para $0 \%$ de umidade, e 4,95 MJ/kg, para $63,4 \%$ de umidade. O valor calculado, para $12 \%$ de umidade, foi de $15,28 \mathrm{MJ} / \mathrm{kg}$. No caso do eucalipto, os pontos foram retirados da literatura (NONNENMACHER et al., 2011), sendo de $17,7 \mathrm{MJ} / \mathrm{kg}$, para $0 \%$ de umidade, e $10,05 \mathrm{MJ} / \mathrm{kg}$, para $40 \%$ de umidade. $\mathrm{O}$ valor calculado, para $12 \%$ de umidade, foi de $15,41 \mathrm{MJ} / \mathrm{kg}$.

Outra hipótese adotada, para o capim elefante, dada as condições para as melhores épocas de colheita como em 1 período de 3 meses consecutivos no início de cada semestre do ano, foi o dimensionamento dos equipamentos de secagem induzida e de compactação (briquetagem e enfardamento) para atender a demanda anual da cerâmica padrão, mantendo uma capacidade de processamento do capim ao longo dos mesmos períodos de colheita, totalizando 6 meses durante o ano, já que não é possível estocar o capim verde por longos períodos, devido à alta probabilidade de aparecimento de fungos, que promoverão o apodrecimento da biomassa, analogamente à cana-de-açúcar (SANTOS et al., 2011), e o risco de incêndio. Ele tem, portanto, que ser seco logo após a colheita e, de preferência, já na forma de bagaço.

O eucalipto, por sua vez, possui a vantagem da secagem natural, pois, após a colheita, as árvores podem ficar ao tempo por meses, até entrar em equilíbrio com a umidade do meio ambiente, podendo assim reduzir sua umidade residual a algo como $30 \%$, dependendo da região. A partir desta, qualquer secagem ulterior pode ser obtida pela "chipagem" (picagem) e secagem dos cavacos, que têm superfície específica muito maior.

O cálculo da capacidade de produção mensal dos equipamentos também levou em consideração o tempo das operações de campo e processamento da biomassa, em torno de 2 semanas. Sendo assim, considerou-se o trabalho correspondente a 7 dias ininterruptos dos equipamentos de secagem induzida (quando considerados) e compactação, de tal forma que haja tempo hábil para todas as outras operações ao longo de um mês.

Com relação ao eucalipto, o dimensionamento dos equipamentos de secagem e compactação, considerou-se a hipótese de que haveriam plantios que supririam a indústria cerâmica ao longo de todo o ano, ao invés de esperar durante 3 anos, no caso do plantio adensado, ou 7 anos, até a primeira colheita do plantio convencional. Dessa forma, analogamente 
ao que foi assumido para o capim elefante, os equipamentos de secagem induzida (quando considerados) e compactação também devem funcionar durante 7 dias ininterruptos, mas seriam de menor capacidade, já que funcionariam durante todos os 12 meses do ano para produzir a mesma quantidade de briquetes.

A área do pátio de secagem do capim elefante, calculado como de 3 ha, aplicável na condição de secagem solar, foi dimensionada para não ultrapassar o limite da altura de "cama" de secagem de $20 \mathrm{~cm}$ e para receber irradiação solar suficiente para secagem, necessitando de 5 revolvimentos por dia com o ancinho tracionado pelo trator, por 3 dias seguidos, havendo disponibilidade de sol. Para tanto, estimou-se a altura em duas situações limítrofes, a primeira, com base na massa verde mensal, com cerca de $60 \%$ de umidade, e sua densidade aparente, de aproximadamente $100 \mathrm{~kg} / \mathrm{m}^{3}$, e a segunda, com base na massa já seca com $12 \%$ de umidade e sua densidade aparente, de aproximadamente $50 \mathrm{~kg} / \mathrm{m}^{3}$. O valor da densidade aparente foi medido a partir da colheita, com equipamento próprio.

Com base em algumas referências (DALGAARD et al., 2000; BUENO, 2002; BANCHI, 2005; SIMÕES, 2008; NUNES, 2014) e nas observações durante o plantio piloto, foram feitas as estimativas do tempo das operações de campo (plantio e colheita) e depreciação dos equipamentos, tomando as especificações dos equipamentos, como o consumo e desempenho dos tratores e colhedeiras, a velocidade média das operações de campo e as distâncias percorridas (PACHECO, 2000). O tempo da operação de secagem induzida foi estimado com base na capacidade de processamento de massa verde pelo tambor rotativo e o tempo de briquetagem e enfardamento com base na capacidade de produção da briquetadeira e da enfardadora, respectivamente.

A estimativa da capacidade dos equipamentos de secagem (tambor rotativo + gerador de ar quente) foi feita com base na quantidade de água a ser secada, em t/h. Foi calculada uma quantidade mínima necessária de energia para vaporização da umidade da biomassa, igualando o calor proveniente da queima de certa fração da biomassa produzida, calculada através do poder calorífico inferior, com o calor de aquecimento e vaporização da água.

Para a secagem induzida, o equacionamento final da área de plantio (Eq. 8) e da fração de biomassa (Eq. 9) utilizada para a secagem é descrito da seguinte maneira:

$$
\begin{gathered}
m_{v}=p_{v} A \rightarrow \dot{m}_{v}=\frac{m_{v}}{\Delta t} \\
m_{s}=p_{s} A \rightarrow \dot{m}_{s}=\frac{m_{s}}{\Delta t} \\
T U_{\text {inicial }}=\frac{m_{v}-m_{s}}{m_{v}} \\
T U_{\text {final }}=12 \%=\frac{m_{12 \%}-m_{s}}{m_{12}} \rightarrow \dot{m}_{12 \%}=\frac{\dot{m}_{s}}{0,88} \cong 1,1364 \dot{m}_{s}
\end{gathered}
$$




$$
\begin{gathered}
P_{\text {vap }}=\left(\dot{m}_{v}-\dot{m}_{12 \%}\right)(c \Delta T+L)=\left(\dot{m}_{v}-1,1364 \dot{m}_{s}\right)(c \Delta T+L) \\
\dot{m}_{\text {secagem }} P C I_{12 \%}=\frac{\Delta Q}{\Delta t}=\frac{P_{v a p}}{\eta}=\frac{P_{v a p}}{0,9} \\
\left(\dot{m}_{12 \%}-\dot{m}_{\text {secagem }}\right) P C I_{12 \%}=E=\left(1,1364 \dot{m}_{s}-\dot{m}_{\text {secagem }}\right) P C I_{12 \%} \\
A=\frac{E}{P C I_{12 \%}\left[1,1364 p_{s}-\frac{\left(p_{v}-1,1364 p_{s}\right)(c \Delta T+L)}{0,9 P C I_{12 \%}}\right]} \\
F=\frac{\dot{m}_{\text {secagem }}}{\dot{m}_{12 \%}}=\frac{\left(\dot{m}_{v}-1,1364 \dot{m}_{s}\right)(c \Delta T+L)}{1,0227 \dot{m}_{s} P C I_{12 \%}}=\frac{\left(p_{v}-1,1364 p_{s}\right)(c \Delta T+L)}{1,0227 p_{s} P C I_{12 \%}}
\end{gathered}
$$

Onde:

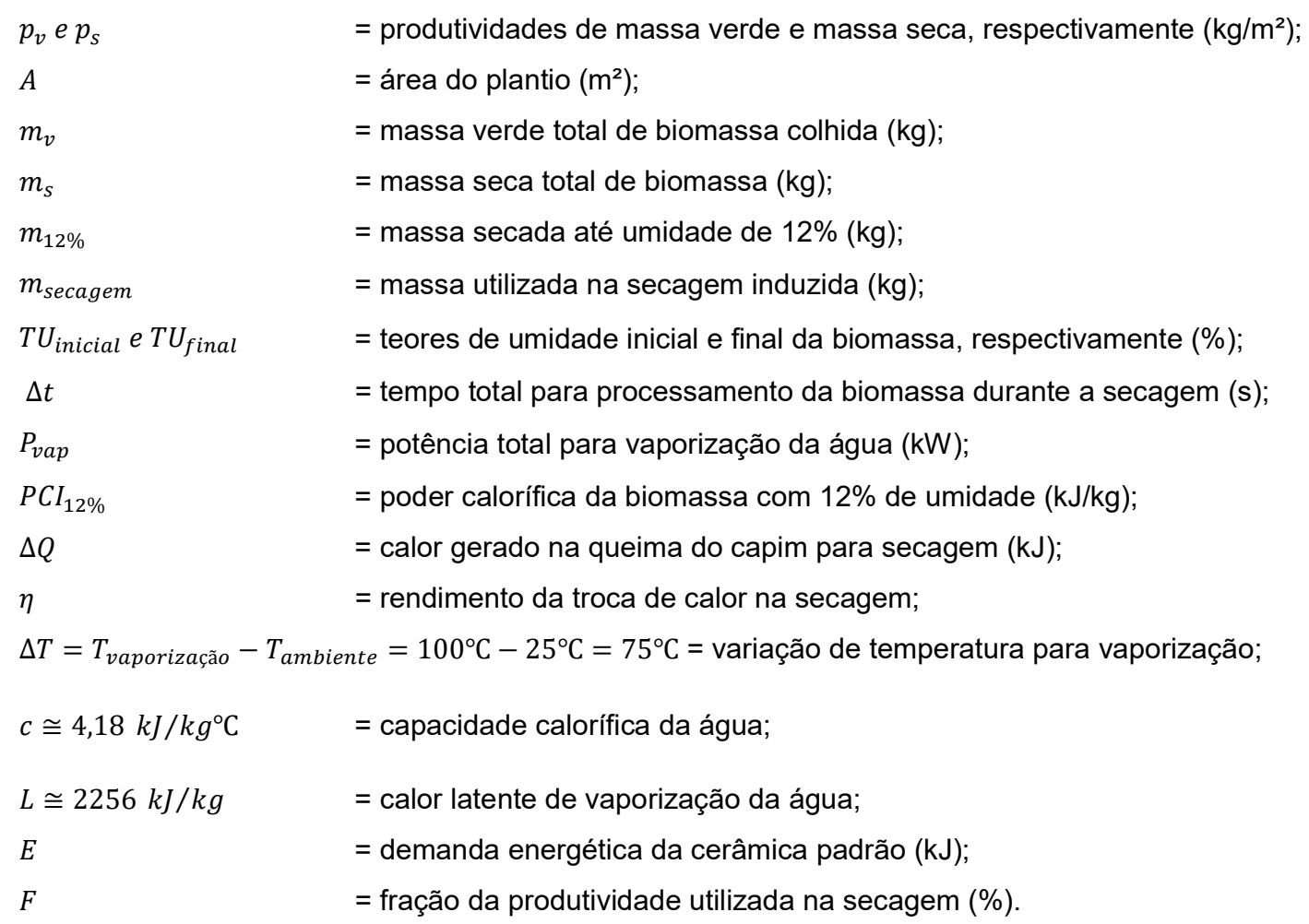

Para a secagem solar, o cálculo da massa de capim produzido com $12 \%$ de umidade e a área de plantio podem ser calculados pelas mesmas equações, apenas considerando, respectivamente, a massa destinada à queima para secagem como sendo nula na Eq. 7 e o termo referente ao calor para vaporização da água: $\left(p_{v}-1,1364 p_{s}\right)(c \Delta T+L)$, como sendo nulo na Eq. 8.

A potência de vaporização do equipamento de secagem foi, então, estimada com um valor de, aproximadamente, $682 \mathrm{kcal}$ de energia necessária para secar $1 \mathrm{~kg}$ de água, valor este que condiz com o valor experimental, em torno de $700 \mathrm{kcal} / \mathrm{kg}$ de água secada, gentilmente informado por Cibele Schiffl, diretora da RCA Máquinas Industriais Ltda, fabricante de equipamentos para secagem de resíduos industriais e florestais. 
Estimou-se o tempo do transporte, com caminhão, do produto final (briquetes ou fardo) entre o local de produção e o consumidor final (indústria cerâmica), considerando uma distância média de $10 \mathrm{~km}$ entre eles.

A metodologia utilizada na confecção do balanço energético seguiu as instruções do $C / G R$ Handbook of Agricultural Engineering, Volume V (1999) (KITANI, 1999). Alguns dados, como os coeficientes energéticos das mudas de eucalipto (MOREIRA et al., 2005) e dos toletes de capim elefante (ZANETTI et al., 2010), foram retirados de outras fontes, mas com a mesma validade e seguindo os mesmos pressupostos para os balanços das duas biomassas, a fim de torná-los comparáveis.

Além dos coeficientes energéticos das mudas e dos toletes, outros 2 foram extraídos de outras referências: Coeficiente energético do formicida (MOREIRA et al., 2005); Coeficiente energético do trabalho humano (ZANETTI et al., 2010)

Como observação, para os plantios de eucalipto, a anualização dos gastos energéticos calculados assumiu a seguinte divisão: os gastos com o pré-plantio e plantio foram considerados como fixos, e contabilizados apenas uma vez, e os gastos com manutenção do plantio, colheita, pós-colheita, compactação e secagem, distribuídos ao longo do tempo e divididos pelo intervalo de tempo de cada plantio, 7 anos para o convencional e 3 anos para o adensado.

\section{RESULTADOS E DISCUSSÃO}

A seguir, serão apresentados os balanços energéticos, para as diferentes situações de plantio, compactação e secagem, de cada biomassa, e feita a análise dos resultados obtidos.

\section{Capim Elefante: Enfardamento vs Briquetagem}

Tabela 1: Balanço energético do capim elefante

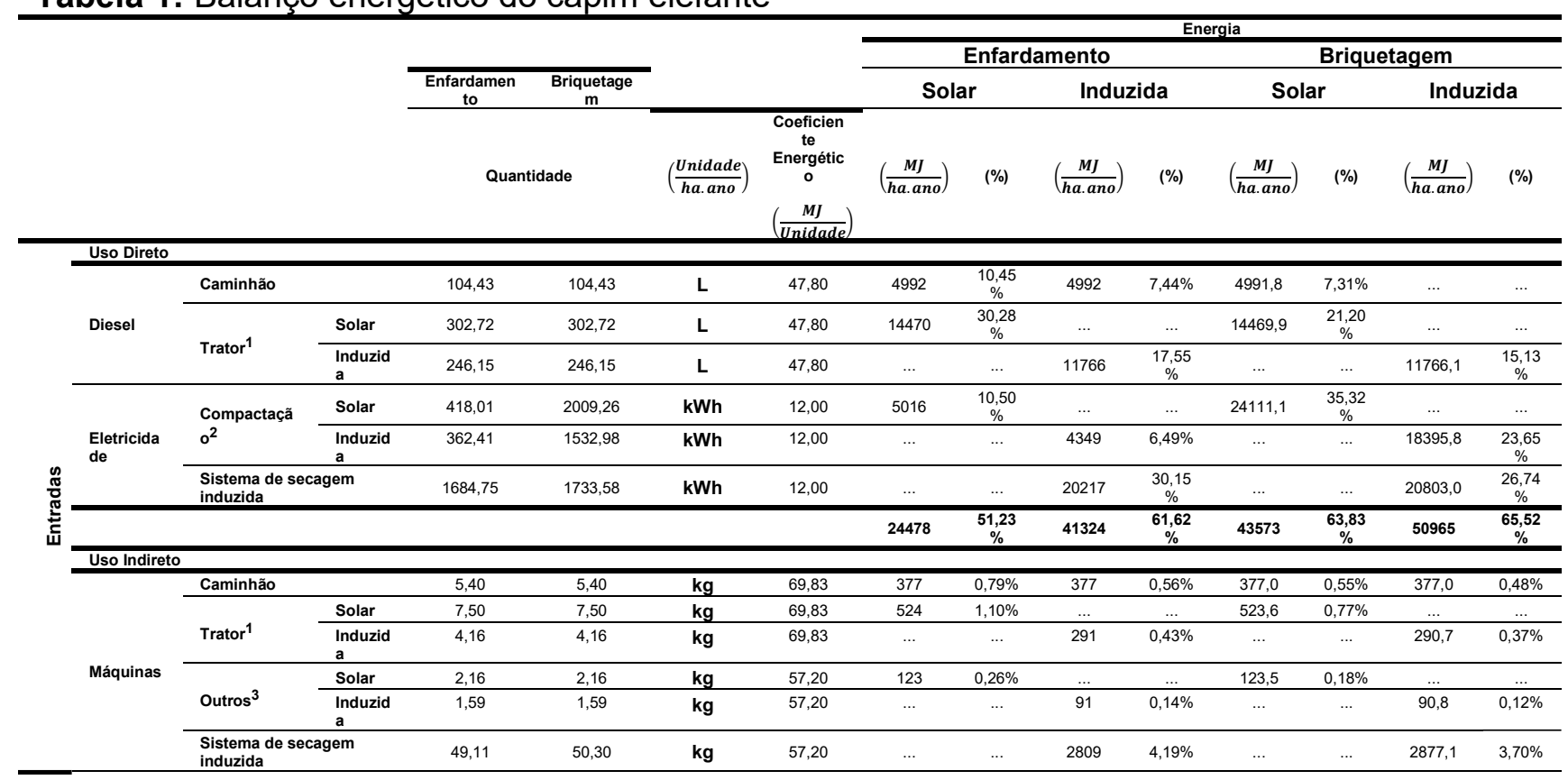




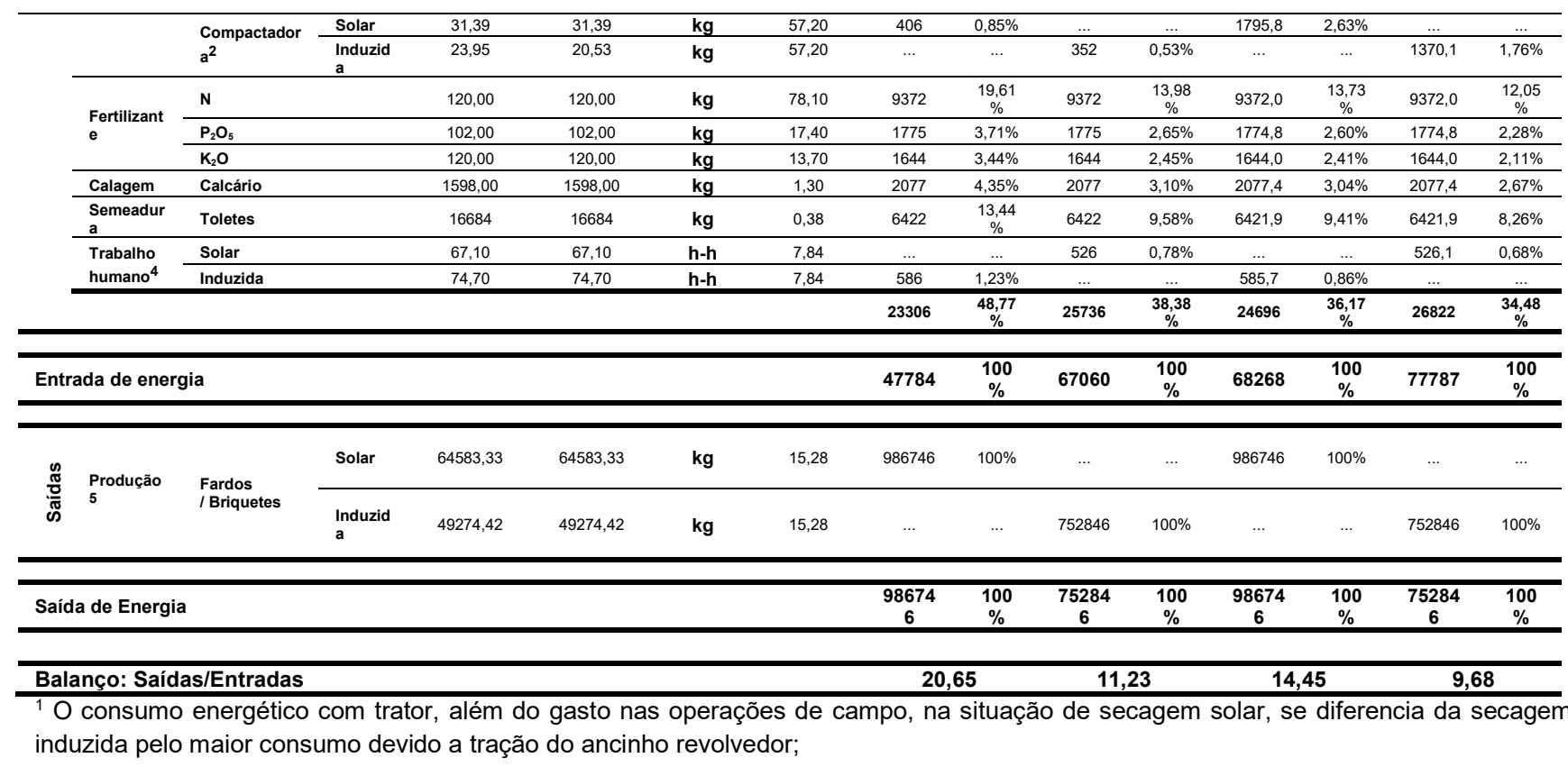

${ }^{2} \mathrm{O}$ consumo energético com a briquetadeira (de pistão mecânico) ou com a enfardadora (horizontal fixa) é menor na secagem induzida, devido a menor quantidade, por hectare, de capim a ser compactado, visto a utilização de parte da produção na própria secagem;

${ }^{3}$ Os "Outros" equipamentos incluem, por exemplo, o distribuidor, o sulcador e a grade. O consumo destes, na situação com secagem solar, inclui, a mais, o ancinho revolvedor;

${ }^{4} \mathrm{O}$ gasto energético com operações inclui, a mais, na situação de secagem solar, o trabalho humano de condução do trator com ancinho para revolvimento;

${ }^{5}$ A produção de briquetes, por hectare, é maior na secagem solar, pois uma parcela da produção de capim é destinada para queima e secagem na induzida.

Pela Tabela 1, comparando as alternativas de compactação do capim elefante, de enfardamento ou briquetagem, é possível notar que há uma diferença muito grande entre as duas opções quando se usa a secagem solar, sendo a primeira opção, o enfardamento, a mais vantajosa, com uma razão do balanço de 20,65 contra 14,45. Pode-se explicar essa diferença, basicamente, pelo maior consumo de energia elétrica da briquetadeira, de, aproximadamente, 3,8 vezes mais que a enfardadora.

Analisando a secagem induzida do capim, em comparação nas duas alternativas de compactação, ela aparece com uma razão do balanço energético apenas um pouco mais alta na briquetagem, de 11,23 contra 9,68, diferentemente do verificado para a secagem solar. Isto se explica ao observar que, a importância do consumo de energia elétrica, principalmente, dos equipamentos de compactação, enfardadora e briquetadeira, que diminui dentro da energia de uso direto, passando de $10,50 \%$ para $6,49 \%$ e de $35,32 \%$ para $23,65 \%$ da energia de entrada, respectivamente, mostrando a preponderância do consumo dos equipamentos de secagem.

Avaliando comparativamente as duas alternativas de secagem, tem-se que, a área de plantio, para suprir a demanda energética da alternativa de compactação + secagem induzida, será de 31,03 ha, contra 23,68 ha da secagem solar, aproximadamente $31 \%$ a mais. Atribui-se essa maior área ao consumo para vaporização da água até atingir $12 \%$ de umidade, o que consome em torno de $24 \%$ da produção, por hectare, para produzir, ao final, a mesma quantidade 
de briquetes ou de fardos que a situação com uso de secagem solar. Em contraponto, na secagem solar, deve-se perceber que haverá outro gasto energético, com o revolvedor e o trator de acionamento, mas bem mais baixo que o consumo do sistema de secagem induzida.

Além dos pontos supracitados, é importante salientar que, em geral, a energia de uso direto representa sempre a maior parcela do total da energia de entrada, variando de $51,23 \%$ até $65,52 \%$, sendo o consumo com energia elétrica o mais significativo, com exceção do enfardamento com secagem solar, que consome uma maior porcentagem com diesel. De qualquer forma, essas informações permitem concluir que a redução do tempo das operações que consomem diretamente energia elétrica e diesel impacta mais significativamente no balanço energético final.

\section{Eucalipto: Plantio Convencional vs Plantio Adensado}

Tabela 2: Balanço energético do eucalipto.

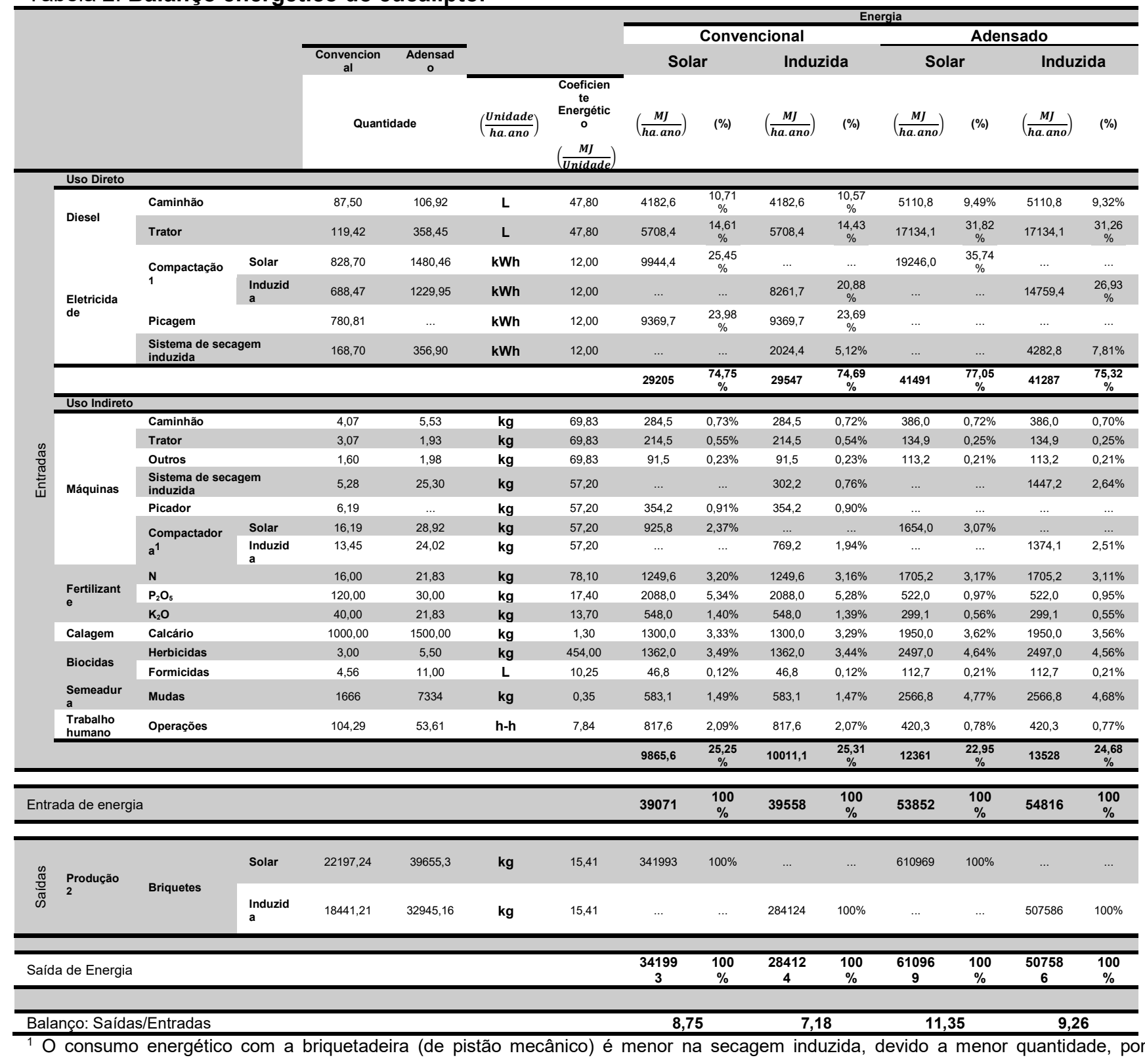


hectare, de capim a ser compactado, visto a utilização de parte da produção na própria secagem;

${ }^{2} \mathrm{~A}$ produção de briquetes, por hectare, é maior na secagem solar, pois uma parcela da produção de eucalipto é destinada para queima e secagem na induzida.

Pela Tabela 2, comparando os diferentes plantios de eucalipto, convencional e adensado, nota-se, claramente, que o plantio adensado é mais vantajoso do ponto de vista energético, com uma razão de balanço de 11,35 e 9,26, para secagem solar e induzida, respectivamente, contra 8,75 e 7,18 do convencional, sendo a secagem solar mais vantajosa que a induzida em ambos, semelhante ao observado para as alternativas do capim elefante.

A energia de uso direto aparece, também, como preponderante dentro da energia de entrada, representando em torno de $69 \%$ no plantio convencional e $76 \%$ no adensado. Desse consumo de energia de uso direto, o diesel aparece como mais significativo no plantio adensado do que no convencional, em torno de $54 \%$, isto se explica pelo maior consumo com operações de plantio, colheita e transporte no plantio adensado.

Avaliando comparativamente as duas alternativas de secagem, tem-se que, no plantio convencional, a área de plantio com secagem induzida calculada será de 82,23 ha, contra 68,31 ha da secagem solar, aproximadamente $20 \%$ a mais. Já no plantio adensado, a área de plantio com secagem induzida será de 46,03 ha, contra 38,24 ha da secagem solar, aproximadamente $20 \%$ a mais. Nos dois tipos de plantio, para a secagem induzida, será consumida em torno de $17 \%$ da produção, por hectare, para promover sua própria secagem. A menor área do plantio adensado é resultado da maior produtividade para atender a mesma demanda.

\section{Briquetagem: Capim Elefante vs Eucalipto}

Comparando a briquetagem do capim elefante com a do eucalipto, nota-se que o balanço energético do capim, tanto para as alternativas de secagem solar quanto induzida, se apresenta mais vantajoso, principalmente em comparação com o plantio convencional do eucalipto, sendo os resultados reproduzidos abaixo (Tabela 3 ):

Tabela 3: Resultados do Balanço Energético para Briquetagem.

\begin{tabular}{|c|c|c|c|}
\hline Método de Secagem & Capim Elefante & \multicolumn{2}{|c|}{ Eucalipto } \\
\cline { 3 - 4 } & & Convencional & Adensado \\
\hline Solar & $\mathbf{1 4 , 4 5}$ & $\mathbf{8 , 7 5}$ & 11,33 \\
\hline Induzida & $\mathbf{9 , 6 8}$ & $\mathbf{7 , 1 8}$ & 9,25 \\
\hline
\end{tabular}

Na Figura 7, estão representadas, na forma de círculos, as áreas plantadas equivalentes necessárias para suprir a quantidade de briquete correspondente à energia demandada pela cerâmica padrão, situada ao centro, para efeitos de comparação. Segundo está análise, o raio de cada círculo é inversamente proporcional à produtividade, isto é, quanto maior esta, menor o raio.

Assim, vê-se que o consumo de energia com transporte, em termos brutos (expressos em $\mathrm{MJ}$, e não em $\mathrm{MJ} / \mathrm{ha}$ ), são bem maiores para o eucalipto, além da maior área que deverá ser 
utilizada a fim de obter a mesma quantidade de briquetes, o que não fica evidente nas tabelas dos balanços energéticos.

Como evidenciado, a área do plantio de eucalipto, convencional e adensado, é, respectivamente, cerca de $189 \%$ e $62 \%$ maior que o plantio de capim elefante, utilizando a secagem solar, correspondendo a uma distância a mais a ser percorrida pelas operações de campo, de $70 \%$ e $27 \%$. Utilizando-se a secagem induzida, esta área é um pouco menor, sendo, respectivamente, cerca de $165 \%$ e $48 \%$ maior que o plantio do capim elefante, correspondendo a uma distância a mais a ser percorrida pelas operações de campo, de $63 \%$ e $22 \%$. A principal causa dessa diferença de área é a menor produtividade do eucalipto.

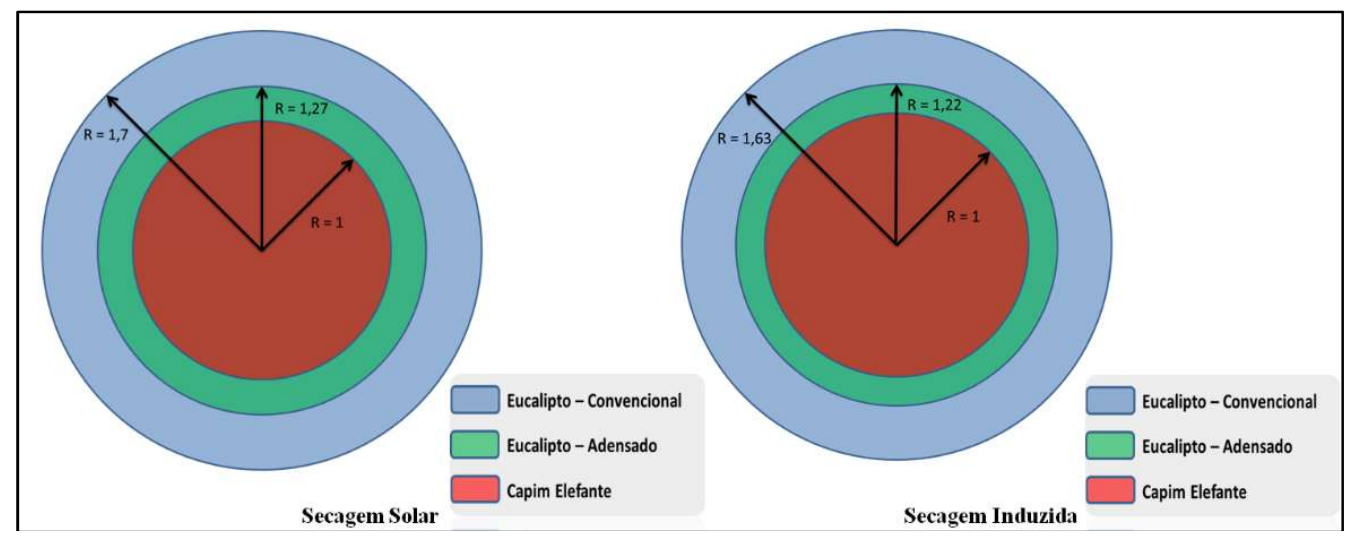

Figura 7: Comparação entre as áreas plantadas de Capim Elefante x Eucalipto

\section{Vantagens e Desvantagens}

A secagem solar apresenta vantagem sobre a induzida. Ainda assim, é importante frisar que existem algumas restrições em relação ao uso da secagem solar, como, por exemplo, a disponibilidade de sol e a dificuldade de manter uma homogeneidade da umidade final, bem como atingir um valor médio relativamente baixo de $12 \%$. Além disso, para operações que requerem alimentação continuada da biomassa, dentro de limites estreitos de variação da umidade, a secagem solar somente, não preenche esta exigência. Apesar das dificuldades expostas, é possível e recomendável combinar as duas alternativas, como, por exemplo, realizar uma présecagem ao sol e finalizar com a secagem induzida, garantindo a secagem até a umidade desejada e a disponibilidade de energia ao longo do ano inteiro.

Embora haja uma vantagem do enfardamento sobre a briquetagem, é preciso avaliar uma forma de adaptar as fornalhas das cerâmicas para receber os fardos que, ao contrário dos briquetes, não possuem uma compatibilidade com o sistema usual de alimentação por rosca sem fim das fornalhas cerâmicas. Mesmo os briquetes, se forem de grande diâmetro, não são passíveis de alimentação pelos sistemas atuais dos fornos. Uma solução é a adoção de briquetes de diâmetro reduzido (ø $40 \mathrm{~mm}$ ), os chamados "bripells", no limite entre briquete e pellet, introduzidos no mercado, há tempos, pela Bripell. Os bripells, portanto, além de possibilitarem uma alimentação mecanizada, e até automatizada, permitem alcançar temperaturas mais altas 
nas fornalhas e nos próprios fornos cerâmicos, e a manutenção da temperatura dentro de limites mais estreitos, por manter o teor de umidade sempre no mesmo intervalo, de 8 a $12 \%$.

Com relação ao uso do capim elefante ou do eucalipto na produção de briquetes, o capim elefante se apresenta mais vantajoso, do ponto de vista energético, sendo possível atingir valores ainda mais altos de produtividade do que o valor de $57 \mathrm{tm} . \mathrm{s} /$ ha.ano, sem irrigação, presente neste trabalho e, assim, obter um balanço energético ainda mais favorável. Já com o uso de irrigação no plantio, pode-se alcançar até mais de $80 \mathrm{tm} . \mathrm{s} / \mathrm{ha}$.ano (FARIA, 1994), o que, apesar do gasto energético com o sistema de irrigação, poderá aumentar o balanço.

É necessário ressaltar algumas dificuldades inerentes ao uso do capim elefante, como o alto teor de cinzas, até certo ponto contornável pelo manejo do plantio, que pode comprometer, em alguns casos, a finalidade pretendida. Uma possível solução existente consiste em lavagens da biomassa, como verificado em experimento fechado conduzido pela Embrapa/CNPAb em 2008, acompanhado pelo IPT, capaz de reduzir os teores de sais a valores bem baixos e aceitáveis para aplicações energéticas, evitando a formação de camadas vítreas nas tubulações, ou a corrosão da caldeira, mas deve-se atentar para o fato de que será contabilizado um gasto de energia a mais com as operações de lavagem e agitação dos banhos, recuperação das águas e com os insumos, no balanço energético.

Sabe-se também que o capim elefante é largamente utilizado para recuperar áreas degradadas (SANTOS et al., 2001), sendo possível sua produção na superfície das células dos aterros sanitários, a partir da aplicação de percolado como fonte de água e de nutrientes (COELHO, 2013; SARAIVA E KONIG, 2013). Em áreas com alta concentração de potássio, resultado comum do excesso de vinhaça, efluente líquido de indústrias sucroalcooleiras, áreas essas passíveis de serem interditadas pela CETESB - Companhia de Tecnologia de Saneamento Ambiental, sabe-se da ação do capim elefante, que atua como "bomba de sucção" de K (potássio), libera essas áreas, em pouco tempo, para receberem novas descargas.

Com relação ao uso do eucalipto, que apresenta uma menor razão de balanço energético, deve-se destacar que, dependendo do tipo de aplicação e das condições do local de plantio, em geral áreas acidentadas, ele pode se apresentar mais vantajoso do ponto de vista prático. Este é o caso do uso de terras com declividade acentuada, e de menor custo, que são inadequadas para o plantio do capim, mas perfeitamente utilizáveis para o eucalipto, quando não se requer colheita mecanizada.

Um estudo recente (LOPES et al., 2009), considerando critérios econômicos e agronômicos, avaliou o capim elefante como sendo uma alternativa de grande potencial para a região do município de Campos dos Goitacazes-RJ, podendo contribuir como substrato para a geração de energia renovável e minimizando o impacto ambiental em áreas degradadas pela exploração da argila, além de reduzir os custos do setor ceramista local, que possui a lenha e/ou o gás natural como recursos energéticos. 


\section{CONCLUSÕES}

Como avaliação geral dos balanços energéticos, o capim elefante mostrou-se em destaque, com um forte potencial de substituição aos atuais combustíveis utilizados (serragem, lenha e cavaco, principalmente) e, também, em comparação com um plantio energético dedicado de eucalipto, visando à produção de briquetes. Ao se tratar do enfardamento, não há dúvidas da vantagem que representa, mas, devido às características técnicas de uso da cerâmica convencional à biomassa, o combustível mais adequado seria o briquete, o qual, mesmo na situação de secagem induzida, o capim ainda apresenta resultados superiores. Rocha et al. (2009) chegou na mesma conclusão sobre o capim elefante em comparação com o cavaco e o óleo BPF para uso em alto forno.

O Brasil, por sua vez, possui clima e solo adequados para o desenvolvimento pleno de certas biomassas energéticas, caracterizadas pela alta produtividade e ciclo curto, por possuir mais de 200 milhões de hectares de áreas degradadas disponíveis para serem recuperadas (COSTA et al., 2008), sendo possível o uso do capim elefante como fonte regeneradora, sendo favorecido seu desenvolvimento dada a alta incidência de horas de insolação, em média 2200 horas de sol por ano (RODRIGUES E MATAJS, 2005), e o alto índice de precipitação, em média de $1797 \mathrm{~mm}$ anuais (ANA, 2005).

Apesar de ainda não ser tão difundida a cultura energética de biomassas no Brasil, mas com um alto potencial capaz de atender até $400 \mathrm{MW}$ da demanda de energia elétrica do país (COELHO et al., 2012), e o fato de o capim elefante ser mais utilizado como ração animal e não como fonte de combustível, espera-se que estes paradigmas sejam vencidos e conduzam a um futuro a ser explorado de novas alternativas de energia.

O eucalipto, pelo seu uso extensivo e intensivo já existente no país e por possuir uma tradição histórica em diferentes aplicações, como a produção de madeira para fabricação de compensados e de papel e celulose, tem recebido maiores investimentos em pesquisa e desenvolvimento, como, por exemplo, nas descobertas genéticas de novos clones, mais produtivos e resistentes, e tem avançado na exploração da biogenética. Isto, em contrapartida, é um campo virgem e fértil, ainda a ser explorado para os capins, no desenvolvimento de variedades, cultivares novos ou híbridos, que multipliquem seus resultados atuais, já bem favoráveis, por fatores que os façam ainda mais competitivos e atraentes.

\section{REFERÊNCIAS}

ANA. Agência Nacional de Águas. Caderno de Recursos Hídricos: Disponibilidade e demanda de recursos hídricos no Brasil. Brasília: Agência Nacional de Águas/Ministério do Meio Ambiente, 2005.

BANCHI, A. D.; LOPES, J.R.; MATOS, M. A.. Consumo de Combustível em Frotas Agrícolas. Revista Agrimotor, São Paulo, v.5, p.8-9, 2005. 
BUENO, O. C.. Análise energética e eficiência cultural do milho em assentantamento rural, Iraberá/SP. Tese (Doutorado em Agronomia) - Faculdade de Ciências Agronômicas da UNESP, Botucatu, 2002.

COELHO, D. C. L.. Atributos químicos de um argissolo e produção de capim elefante decorrentes da aplicação de percolado de aterro sanitário. Dissertação (Mestrado em Ciência do solo) - Universidade Federal Rural do Semiárido. Mossoró, 2013.

COELHO, S. T.; DA SILVA, O. C.; CONSÍGliO, M.; PISETTA, M.; MONTEIRO, M. B. C. A.. Panorama do Potencial de Biomassa no Brasil. PROJETO BRA/00/029. Capacitação do setor elétrico brasileiro em relação à mudança global do clima. ANEEL, 2012.

COSTA, J. S.; ALVARENGA, M. I. N.; MELLONI, E. G. P.; MELLONI, R.. Proteção de taludes e controle de erosão com técnicas de bioengenharia. EPAMIG: Informe Agropecuário, Belo Horizonte, v.29, n.244, p.75-88, 2008.

DALGAARD, T.; HALBERG, N.; PORTER, J. R.. A model for fossil energy use in Danish agriculture used to compare organic and conventional farming. Agriculture, Ecosystems \& Environment, v.87, p.51-65, 2001. DOI: $\underline{\text { http://doi.org/10.1016/S0167-8809(00)00297-8 }}$

DIAS, J. M. C. S.; SOUZA, D. T.; BRAGA, M.; ONOYAMA, M. M.; MIRANDA, C. H. B.; BARBOSA, P. F. D.; ROCHA, J. D.. Produção de briquetes e péletes a partir de resíduos agrícolas, agroindustriais e Florestais. Embrapa Agroenergia, Brasília, 2012.

DINARDI, A. J.. Viabilidade técnica e econômica de povoamentos de Eucalyptus spp. sob diferentes espaçamentos visando a produção de biomassa para energia. Tese (Doutorado) - Universidade Estadual Paulista, Botucatu, 2014.

EPE. Nota Técnica DEA 13/14: Demanda de Energia 2050. Rio de Janeiro: EPE, 2014.

FARIA, V. P.. Formas de uso do capim-elefante. In: PASSOS, L.P.; CARVALHO, L.A.; MARTINS, C.E. II Simpósio sobre capim-elefante. Juiz de For a: EMBRAPA-CNPGL, 1994. p.139-148

GEA. Toward a Sustainable Future. Cambridge: Cambridge University Press, 2012.

GREENPEACE. Revolução energética: a caminho do desenvolvimento limpo: Cenário Brasileiro 2013. 2013.

IPCC. Climate Change 2007: the physical science basis. Cambridge: Cambridge University Press, 2007.

KITANI, O.. Energy and Biomass Engineering: CIGR Handbook of Agricultural Engineering. Michigan: The American Society of Agricultural Engineers, 1994.

LANA, G. C.. Efeito da dimensão de toras no processo de colheita florestal e seus impactos no custo e na qualidade do carvão vegetal. Dissertação (Mestrado em Engenharia Florestal) - Universidade Federal do Paraná, Curitiba, 2012.

LOPES, M. V. F.; JUNIOR, M. E.; FILHO, L. R.; COELHO, A. A.; DE SOUZA, C. L. M.. Uso sustentável do solo para produção de capim-elefante, pennisetum purpureum, no município de Campos dos Goitacazes, RJ. In: ENCONTRO NACIONAL DE ENGENHARIA DE PRODUÇÃO, 19. A Engenharia de Produção e o Desenvolvimento Sustentável: Integrando Tecnologia e Gestão. Anais. Salvador, 2009.

MOREIRA, C. R.; GUERRINI, I. A.; BIAGGIONI, M. A. M.. Avaliação energética do cultivo de eucalipto, com e sem composto de lixo urbano. Revista Energia na Agricultura, Botucatu, v.20, n.4. p.1-19, 2005.

NONNENMACHER, H.; FRANTZ, J. C.; DIAS R. DE M.; STANGARLIN, H. W.. Análise da influência do teor de umidade no poder calorífico em combustível sólido para geração de vapor d'água. In: SALÃO DE ENSINO E DE EXTENSÃO DA UNISC, 2. Anais. Santa Cruz do Sul. EDUNISC, 2011.

NUNES, W. C.. Viabilidade técnica e econômica da adubação a lanço antecipada e na linha de semeadura do feijoeiro em diferentes sistemas de cultivo. Dissertação (Mestrado em Engenharia Agrícola) - Universidade Federal de Lavras, Lavras, 2014. 
PACHECO, E. P.. Seleção e custo operacional de máquinas agrícolas. Rio Branco: Embrapa Acre, 2000.

QUIRINO, W. F.. Briquetagem de resíduos ligno-celulósicos. IBAMA: 2002.

ROCHA, E. P. A.; SOUZA, D.F.; DAMASCENO, S. M.. Estudo da viabilidade da utilização de briquete de capim como fonte alternativa de energia para queima em alto-forno. CONGRESSO BRASILEIRO DE ENGENHARIA QUÍMICA EM INICIAÇÃO CIENTÍFICA, 8. Anais. Uberlândia, 2009.

RODIGHERI, H. R.; PINTO, A. F.; DHLSON, J. C.. Custo de produção, produtividade e renda do eucalipto conduzido para uso múltiplo no norte pioneiro do estado do Paraná. Embrapa Florestas, 2001.

RODRIGUES, D.; MATAJS, R.. Um banho de Sol para o Brasil: o que os aquecedores solares podem fazer pelo meio ambiente e a sociedade. São Lourenço da Serra: Instituto Vitae Civilis, 2005.

SANTOS, A. C.; SILVA, I. F.; LIMA, J. R. S.; ANDRADE, A. P.; CAVALCANTE, V. R.. Gramíneas e leguminosas na recuperação de áreas degradadas: efeito nas características químicas de solo. Revista Brasileira de Ciência do Solo, v.25, p.1063-1071, 2001. DOI: http://doi.org/10.1590/s0100$\underline{06832001000400028}$

SANTOS, M. L.; LIMA, O. J. de; NASSAR, E. J.; CIUFFI, K.J.; CALEFI, P. S.. Estudo das condições de estocagem do bagaço de cana-de-açúcar por análise térmica. Quím. Nova, São Paulo, v.34, n.3, p.507511, 2011. DOI: http://doi.org/10.1590/s0100-40422011000300024

SARAIVA, V. M.; KONIG, A. Produtividade do capim-elefante-roxo irrigado com esgoto doméstico tratado no semiárido potiguar e suas utilidades. Holos, v.1, p.28-46, mar. 2013. DOI:

http://doi.org/10.15628/holos.2013.1251

SECRETARIA DE GEOLOGIA, MINERAÇÃO E TRANSFORMAÇÃO MINERAL. Anuário Estatístico 2007: Setor de transformação de não-metálicos. Brasília: SGM, 2007.

SILVA, E.; ROCHA, C. R.. Eucalipto e capim elefante: características e potencial produtivo de biomassa. Revista Agrogeoambiental, Pouso Alegre, v.2, n.1, p.143-152, 2010.

SIMÕES, D.. Avaliação econômica de dois sistemas de colheita florestal mecanizada de eucalipto. Dissertação (Mestrado em Agronomia/Energia na Agricultura) - Universidade Estadual Paulista, Botucatu, 2008.

WILCKEN, C. F.; LIMA, A. C. V.; DIAS, T. K. R.; MASSON, M. V.; FILHO, P. J. F.; POGETTO, M. H. F. A.. Guia prático de manejo de plantações de eucalipto. Botucatu: FEPAF, 2008.

ZANETTI, J. B.; MORAIS, F. R. DE; ALVES, B. J. R.; BODDEY, R. M.; URQUIAGA, S.; SOARES L. H. DE B.. Balanço de energia na produção de capim-elefante em condições experimentais. Embrapa Agrobiologia: Seropédica, Rio de Janeiro, p.7-16, 2010.

ZHU, X.; LONG, S. P.; ORT, D. R.. What is the maximum efficiency with which photosynthesis can convert solar energy into biomass?. Current Opinion in Biotechnology, v.19, n.2, p.153-159, 2008. DOI:

http://doi.org/10.1016/j.copbio.2008.02.004 